Participatory Educational Research (PER)

Vol. 1(2), pp. 13-20, December, 2014

Available online at http://www.partedres.com

ISSN: 2148-6123

http://dx.doi.org/10.17275/per.14.07.1.2

\title{
Active and Accountable Social Inquiry: Implications and Examples
}

\begin{tabular}{|c|c|}
\hline & $\begin{array}{l}\text { Norma RA Romm }{ }^{*} \\
\text { University of South Africa }\end{array}$ \\
\hline Article history & This article is based on my inaugural lecture that I delivered at the \\
\hline $\begin{array}{l}\text { Received: } \\
15.06 .2014\end{array}$ & $\begin{array}{l}\text { University of South Africa on } 6 \text { November 2013. The topic of the } \\
\text { inaugural lecture was "active and accountable social inquiry" In the }\end{array}$ \\
\hline in revised form: & inaugural address I focused on what it might mean to practice what \\
\hline 17.06 . & I call active as well as accountable social research. I explained the \\
\hline $\begin{array}{l}\text { Accepted: } \\
24.06 .2014\end{array}$ & $\begin{array}{l}\text { various research contexts in which I, with colleagues, have used the } \\
\text { term "active" to characterize research where responsibility is taken }\end{array}$ \\
\hline Key words: & \\
\hline $\begin{array}{l}\text { active research, accountable } \\
\text { research, research participants, } \\
\text { co-inquiring, co-learning }\end{array}$ & $\begin{array}{l}\text { research implies that one engages research participants in processes } \\
\text { not led solely by the initiating researchers, but is a product of a } \\
\text { variety of inputs and decisions about the meaning of the research } \\
\text { and its potential action implications. The approach to active } \\
\text { research that is detailed in this article is pertinent to this journal on } \\
\text { Participatory Educational Research, which is aimed at publicizing } \\
\text { various efforts on the parts of researchers to develop a more } \\
\text { participatory style of inquiry. Active research is one way of } \\
\text { developing such a style. }\end{array}$ \\
\hline
\end{tabular}

* Address for correspondence: norma.romm@gmail.com 


\section{Use of the Term "Active" to Characterize Research/Social Inquiry Some Examples of My Use of the Term "Active" in Research Contexts}

I first used the term active to refer to research approaches when writing an article with a former PhD student who was from Taiwan. His name is Cheng-Yi Hsu. He was one of my students while I was in the UK working at the University of Hull - we had many postgraduate students from all over the world. This student was studying power distance in the Kaohsiung Harbour in Taiwan using as his conceptual starting point Geert Hofstede's book entitled Culture's Consequences: International Differences in Work-Related Values first published in 1984.

Hofstede argues that different countries may have different orientations to power distance in the workplace that are related to their national culture. High power distance implies that workers expect those in positions of authority in the workplace to make decisions, and they do not expect to be consulted. Low power distance implies that workers expect a more democratic culture to prevail. Now I suggested to Cheng-Yi that by taking an active approach he could offer a novel possibility for exploring power distance, which does not reinforce rigid cultural conceptions.

For example, I suggested that he could explore the ambiguities in the culture and could use this as a basis for seeing whether workers could become more involved in decision-making and where managers might appreciate this involvement. The "activity" on his part meant that as a researcher instead of just attempting to record what seem to be the dynamics of interaction between workers and managers, one could explore possibilities for people's reviewing experienced patterns that both parties may find restrictive. This required mediation skills on Cheng-Yi's part, where he acted as mediator in trying to express to each party the others' concerns; and this (it could be argued) opened avenues for shifting somewhat their way of orienting to each other. The article that we wrote subsequent to his $\mathrm{PhD}$ was published in 2002 in a management journal called Omega. It was entitled "Reconsidering the exploration of power distance: an active case study approach" (Romm \& Hsu, 2002, pp. 403414). Essentially the argument is that research always makes some difference to the way that social outcomes pan out: even research that aims to be neutral (or that strives for so-called objectivity) can easily serve to reinforce existing structures, unwittingly. Active research means that researchers take some responsibility for the way in which their research might impact on the social world of which research is a part, as I summarized this in my book called Accountability in Social Research that was published in 2001.

The second time that I used the term "active" was when co-conducting an evaluation of some management training programmes in the East Riding County Council in the UK. The people in charge of the training programmes were interested in what managers had learned and whether they were able to apply what they had learned from the management courses. Again I suggested this time to co-researcher Peter Adman that we could follow a style of interviewing where at the moment of the interview we already could enable managers as well as staff being interviewed to re-reflect on how they were interacting with each other. In this case, parallel with the training programme for managers, the organization was implementing a 360 degree feedback scheme where staff had the opportunity to comment on their managers' management style.

When conducting the interviews our aim was not just to "probe" people's experiences of this, but to help them to consider ways in which the training in combination with the feedback system could serve as an opportunity for strengthening the communicative relationships that 
potentially existed between managers and staff. One article that came out of this research was called "Exploring the complexity of human dynamics within 360-degree feedback processes: the development of (active) qualitative inquiry". This was published in the Journal of Business and Society (2004, pp. 170-189).

Our active position that we took was consistent with some arguments that Holstein and Gubrium had been developing around what they called "active interviewing" (as published in a book on this in 1995). They suggested that active interviewing can be characterized as follows:

Asking the respondent to address a topic from one point of view, then another, is a way of activating the respondent's stock of knowledge... The contradictions and complexities that may emerge from positional shifts are rethought to signal alternative horizons and linkages. (1995, pp. 77-78)

Agreeing with and extending Holstein and Gubrium's understanding, we recognized that the interviewing process in the organization could be used as an occasion to elicit complexities as we discussed the "topics" with people: so that people became (more) aware of different ways of addressing the issues at stake. In this case one of the issues was the question of how trust can be developed via a 360 degree feedback process, rather than it leading to conflict between managers and workers. As people are asked to consider issues from different angles, their horizons become extended rather than univocal visions being reinforced. Again one can see that our aim was to initiate processes of reflection on the part of the participants.

Another occasion in which the same terminology of "active" was employed was in the doing of research that Veronica McKay and I co-organized exploring HIV and AIDS in the informal economy in Zambia (2005-2006). In the case of this write up we together reflected on what made "active research" different from the broader category of action research (and traditional understandings of action research). One of our articles was called "Active research towards the addressal of HIV/AIDS in the informal economy in Zambia: Recognition of complicity in unfolding situations". This was published in 2008 in the journal called Action Research (Special Issue on Development).

We stated our position vis à vis action research as follows:

We did not aim, as Coghlan and Shani suggest for action research inquiry, to set up cycles of inquiry involving "diagnosing, planning action, taking action and evaluating action" (Coghlan \& Shani, 2005, p. 534). ... . Rather, we followed what we called a more nuanced view of the transformative possibilities of action research - where trajectories of change cannot be clearly determined as part of the action research remit. (McKay \& Romm, 2008, pp. 151-152)

It should also be mentioned that in this project, we used what is called a mixed-method design, using a variety of approaches, including questionnaires, rapid assessment workshops, peer education, and dialoguing with additional stakeholders at a national workshop. But instead of taking these various phases of the research "off the shelf" (as Midgley, 2000, puts it), we (re)worked the various research approaches. These became adapted through infusing each one with a consciously considered intervention component, recognizing again that as soon as one uses "methods" one is making a difference in some way to the manner in which participants and wider audiences will "see" the issues that are being explored. 


\section{Using Questionnaires with “Active" Intentions to De-Rigidify Constricted Meaning-Making}

Let us consider as one example the way that we used the questionnaire in the Zambian project to try to open for reconsideration that women have little or no say in the decisions re condom use. One of the questions asked people to consider for instance, whether condom use is negotiated. Already by asking this as one option for how decisions re condom use are made, one raises the possibility that it can become more negotiated. In other words, already by posing questions in a certain way, one can open up options for seeing (and for action) not previously given attention in terms of restricted cultural expectations.

There are myriads of examples of how questionnaires can easily serve to reinforce rigidified cultural constructions. Some of these I discussed in my book called New Racism: Revisiting Researcher Accountabilities (2010). Here I argued that when one uses uncritically terms such as "race" in a questionnaire, one can unwittingly serve to limit people's imagination to thinking that race is a biological or cultural given in societies, with implications for how people regard each other and possibilities for interchange across categorical distinctions.

I will offer an extensive quote from my book on New Racism (2010, p. 127) to illustrate this point (where I am also citing a few other authors to emphasize this point, starting with Michael Omi): Here is how I stated it:

In whatever way the discussion around racialized categorization is opened up, Omi considers it crucial that researchers/analysts display "imagination" in their research work and do not slip into "treat[ing] the category of race in an unproblematic fashion" (2001, p. 260). He thus calls on social scientists to display a sensitivity toward "problematizing race in our work" (Omi, 2001, p. 260).

Milner IV too suggests that in terms of what is called Critical Race Theory (CRT) ... researchers are urged to consider the following questions:

What do my [the] participants believe about race and culture in society and education, and how do they and I attend to the tensions inherent in my and their convictions and beliefs about race and culture in the research process? (2007, p. 395)

Milner IV here remarks that If one leaves in abeyance these questions, and uses the category of "race" without giving participants an opportunity to discuss their views of race, the questions are silenced.

And as Harris-Lacewell comments too, this means that certain notions remain uninterrogated through the way in which the research is formulated (2003, p. 234).

In a recent article in a journal on qualitative-oriented approaches (International Journal of Qualitative Methods), I concentrated on developing further the argument regarding taking some responsibility for the way in which we use categories within questionnaires (Romm, 2013). The article is entitled: "Employing questionnaires in terms of a constructivist epistemological stance: Reconsidering researchers' involvement in the unfolding of social life". As I phrased it there:

Attempts can thus be made to use questionnaires so that they undermine socially rigidified categories and meaning-making that are unnecessarily limiting in terms of their social consequences. That is, questionnaires can intentionally enable respondents/participants to rethink issues that they may not have considered before and expose them to ways of seeing by asking them to respond to questions phrased in 
a certain way. This can also open more spaces for audiences (reading "reports") to rereflect on issues raised, and to participate in (further) "collective deliberation" (2013, p. 661).

In my book on New Racism (2010) I offered some examples of how this can be done with questionnaires which concentrate on an exploration of "race". I suggested that in the questionnaire itself this term can be put in quotation marks and respondents can be asked to reflect on why they think it has been placed in quotation marks. (This would imply creating an open-ended question on this; which means that when the report is written up there is additional information for audiences to consider, rather than seeing race as a "thing" that is given in the social world and that has a univocal meaning.)

\section{Being on the Lookout, no Matter What Methods Are Used, for Ways of Rendering Research More Active}

My point is that on all occasions, researchers can and should be on the look-out for ways in which they can render their research more active in the sense of opening up new avenues for thinking and acting on the part of actors in the social world.

This same position re taking responsibility is expressed in an article that I recently coauthored with Norma Nel and Dan Tlale in the South African journal of Education (2013). The article is entitled "Active facilitation of focus groups: Co-exploring with participants the implementation of inclusive education". As Norma Nel explained in her recent inaugural, the project was geared to a comparative analysis of teachers' roles in inclusive education in Finland, Slovenia, Lithuania, China, England and South Africa - and it consisted of various research phases that were administered across the different countries. I came into the project at the point of the conduct of the focus groups in South Africa, and we decided in this case to ask participants also to offer feedback to us on the sessions. We considered the sessions as active in that right from the beginning we indicated to participants that we were all exploring the issues together and all would hopefully be learning from one another, thus mutually extending our understandings.

The idea was not to presume to "find out" what participants were thinking, but to engage a conversation in which people - participants as well as initiating researchers (facilitators) could develop ideas/insights via the exchange. Participant feedback indicated that participants did indeed feel that this was a beneficial outcome of the research and they also requested us to take the issues forward to other forums where their voices could be heard. We arranged for a further meeting with a district officer (who was one of Norma Nel's MA students) and she in turn agreed that a meeting should be set up comprising the initiating researchers (ourselves) with focus group participants and additional district officers as well as someone from head office, with a view to exploring challenges and possible ways of addressing them.

One of the anonymous reviewers of our article, in considering the question of the "placement" of our discussion, commented that our active approach "highlights the importance of more engaged educational research with a pragmatist twist and a transformative agenda". We would have liked to quote this account of what the term "active" meant for this reviewer. Her sentence well summarizes the gist of what active research can be said to mean in practice.

The pragmatist twist here refers to a specific epistemological orientation, which is not realist in the sense of defining knowledge as representation of some reality out there independently of people's experiences and interpretations (including those of the researcher). As we noted in 
this article: "Our pragmatism can be classed as what Onwuegbuzie, Johnson and Collins (2009, p. 1268) refer to as a 'dialectical pragmatism'; this form of pragmatism embraces a philosophy of 'careful listening to multiple perspectives' rather than upholding a strong form of realism".

In most of my books and articles to date I explore the position of epistemological constructivism as an alternative to realism. Briefly put, I have suggested that what I call a trusting constructivist position $(2001,2002)$, develops constructivism in the direction of focusing on research accountabilities. In such a position, researchers can earn the trust of research participants and wider audiences by signalling that they are willing to engage in discussion around their research practices, including around the implications of any "results/interpretations" that are presented (in draft form for discussion). I suggest that when one operates in terms of a trusting constructivist: position, one is geared to encouraging an expansion of horizons (for seeing and acting) on the part of all concerned. What is also important in terms of a trusting constructivist argument is that ways of seeing (which carry attendant options for action) have to be justified discursively via processes of engaging in discourse and indicating that one is taking seriously a variety of inputs.

\section{Considering Questions of Epistemology as Linked to Revisiting Power Relations}

What is also important to note is that the pragmatic epistemological twist, where research is not judged in terms of its claims to be more or less objective (or value-free), but is judged on other criteria, is often seen as a site of political power. The power to define what it means to "know" often means that certain epistemological positions become rendered inferior in the academic as well as the social world. Chilisa states the imperative to offer alternatives to dominant definitions of "science" as being part of a "decolonizing ethics" (where ethics is not predicated on Western-oriented models of scientific knowing). As she strongly puts it:

It can be argued that the exclusion of other epistemologies or knowledge systems is a methodological flaw and a violation of ethics. (2007, p. 199)

This article of hers is in a book called Challenges and Responsibilities of Social Research in Africa: Ethical Issues (2007). (My chapter in this book is called "Issues of accountabilty in survey, ethnographic and action research".) Like Chilisa I put forward an alternative to (dominant) realist epistemological stances by referring to a constructivist approach which, as I suggest here:

Focuses on the value of discursive exchange between different ... ways of coconstructing and working with information (as humanly mediated). (2007, p. 53)

In summary, the focus is not on trying to find ways to authorize any claim to "know", but rather is on encouraging discursive exchanges between people, including professional researchers and others, with a view to people extending their initial understanding of options for seeing and acting. (In my book on Accountability in Social Research I detail my suggestions for a trusting constructivist approach, where researchers can earn trust in terms of the relationships that are built up with research participants and wider audiences.)

A similar epistemological and ethical approach to social inquiry can also be said to be epitomized in the way that some of us in the ABET department involved in evaluating the impact of the Kha Ri Gude mass literacy campaign have approached the research process.

Thus far I am aware only of the team of researchers of which I am part. Our methodological process so far has included a content analysis of a sample of past learners' portfolios, 
combined with focus group discussions which we facilitated (with the primary facilitator speaking in mother tongue to the participants, while doing some translations along the way so that the other facilitators could also become involved to some extent). In these discussions, past learners and teachers had the opportunity to express and discuss ways in which the campaign can be said to have touched their lives, as well as what may be further needed to enhance the value of the campaign. There are three points in this regard that I would like to highlight:

(1) Firstly, our accountability as researchers does not rest on any claim to be discovering something outside of the context of interaction in which the facilitators with participants are exploring the issues as experienced. We recognize that the context of interaction contributes to generating the "data" that emerges and we intend to take account of this, for example, when constructing (and discussing) reports.

(2) Secondly, we considered it important to take into account how the research endeavour might be seen by participants and how this (the presence of people coming and speaking to them about Kha Ri Gude) might feel for them. Hence we included a process of seeking feedback from them so that they are aware that we care about how they have experienced the focus group sessions and that we are interested in hearing about this.

(3) Thirdly, we have also sought to locate, with participants, certain action options to follow up (with others, including some government officials) - in line with participants' felt experiences of what is needed. This, it should be noted, is different from taking a stance of relinquishing responsibility for whether anyone may notice reports that become produced (as indeed with some researchers who argue that their responsibilities end once reports have been constructed).

\section{Use of the Term "Inquiry"}

It remains now for me to comment on why I have used the word "inquiry" as part of the inaugural address title. This is because I am trying to focus on how people (professional researchers and others) can inquire together and learn together as well as discuss action options together through processes of co-exploration. I am not sure if the term "research" well captures this orientation. Nevertheless, one could also use the term "research" as I have in some of my writings - with the proviso that this need not go hand in hand with an epistemological realism, but rather is understood as re-search or re-looking at issues of concern through a focused inquiry process.

I hope that I have given some flavour of how I see that research (or focused inquiry) itself can and does make a difference to the unfolding of social outcomes - whether this is witting or unwitting. The term active research expresses a conscious intention to consider as part of one's responsibility the potential impact (as also discussed with others) of the doing of any social research.

\section{References}

Chilisa, B. (2007). Decolonizing ethics in social research. Issues of accountability in survey, ethnographic, and action research. In A. Rwomire \& F. B. Nyamnjoh (Eds.), Challenges and responsibilities of social research in Africa: Ethical issues (pp. 199208). Addis Ababa: The Organization for Social Science Research in Eastern and Southern Africa (OSSREA). 
Coghlan, D., \& Shani, A.B. (2005). Roles, politics and ethics in action research design. Action Research 18(6): 533-545.

Harris-Lacewell, M. (2003). The heart of the politics of race: Centering Black people in the study of White racial attitudes. Journal of Black Studies 34(2): 222-249.

Hofstede, G. (1984). Culture's Consequences: International Differences in Work-Related Values. London: Sage.

Holstein, J.A., \& Gubrium, J.F. (1995). The Active Interview. London: Sage.

McKay, V.I., \& Romm, N.R.A. (2008). Active research toward the addressal of HIV/AIDS in the informal economy in Zambia: Recognition of complicity in unfolding situations. Action Research 6(2): 149-170.

Midgley, G. (2000). Systemic Intervention: Philosophy, Methodology and Practice. New York: Kluwer Academic/Plenum Publishers.

Milner IV, H.R. (2007). Race, culture and researcher positionality: Working through dangers seen, unseen, and unforeseen. Educational Researcher 36(7): 388-400.

Omi, M.A. (2001). The changing meaning of race, in N. Smelser, W.J. Wilson, \& F. Mitchell (eds.), America Becoming (pp. 243-262). Washington: National Academy Press.

Onwuegbuzie, A.J., Johnson, R.B., \& Collins, K.M.T. (2009). Assessing legitimation in mixed research: A new framework. Quality and Quantity, 45(6):1253-1271.

Romm, N.R.A., \& Hsu, C-Y. (2002). Reconsidering the exploration of power distance: An active case study approach. Omega 30(6): 403-414.

Romm, N.R.A., \& Adman, P. (2004). Exploring the complexity of human dynamics within 360-degree feedback processes: The development of (active) qualitative inquiry. Journal of Business and Society 17(1\&2): 170-189.

Romm, N.R.A., Nel, N.M., \& Tlale, L.D.N. (2013). Active facilitation of focus groups: Coexploring with participants the implementation of inclusive education. South African Journal of Education 33(4) (article 811).

Romm, N.R.A. (2001). Accountability in Social Research: Issues and Debates. New York: Kluwer Academic/Plenum.

Romm, N.R.A. (2002). A Trusting Constructivist approach to systemic inquiry: Exploring accountability, Systems Research and Behavioral Science, 19(5): 455-467.

Romm, N. R. A. (2007). Issues of accountability in survey, ethnographic, and action research. In A. Rwomire \& F. B. Nyamnjoh (Eds.), Challenges and responsibilities of social research in Africa: Ethical issues (pp. 51-76). Addis Ababa: The Organization for Social Science Research in Eastern and Southern Africa (OSSREA).

Romm, N.R.A. (2010). New Racism: Revisiting Researcher Accountabilities. New York: Springer.

Romm, N.R.A. (2013). Employing questionnaires in terms of a constructivist epistemological stance: Reconsidering researchers' involvement in the unfolding of social life.

International Journal of Qualitative Methods 12: 651-669. 